TRABAJOS ORIGINALES

\title{
Efecto ahorrativo de la proteína usando niveles altos de energía y obtención de la relación optima energía digestible/proteína digestible en dietas para el crecimiento de Oreochromis niloticus (L)
}

\section{Protein-sparing effect with high energy levels and obtaining the optimum digestible energy/ digestible protein ratio in growth diets to Oreochromis niloticus (L.)}

\author{
Felix Walter Gutierrez ${ }^{1,2}$, Máximo Quispe ${ }^{1}$, Luz Valenzuela ${ }^{1}$
}

\begin{abstract}
1. Facultad de Ciencias Biológicas, Universidad Nacional Mayor de San Marcos.

2 Dirección para correspondencia: 10642 Mallard DR. Garden Grove, CA 92843, USA.

Felix Gutierrez. E mail: gutierrez_romero@sbcglobal.net Máximo Quispe Chau. E mail: mquispe@alicorp.com.ec Luz Valenzuela. E mail: luzmvalenzuela@yahoo.com
\end{abstract}

Citación:

Gutierrez F.W., M. Quispe, L. Valenzuela. 2014. Efecto ahorrativo de la proteína con niveles altos de energía y obtención de la relación optima energía digestible/proteína digestible en dietas para el crecimiento de Oreochromis niloticus (L.). Rev. peru. biol. 20(3): 227 - 232 (Marzo 2014)

\section{Resumen}

Se evaluó el efecto ahorrativo de la proteína usando dietas altas en energía. Se utilizó un diseño factorial para medir la interacción de dos niveles de proteína (30\% y $35 \%$ ) y dos niveles de energía digestible (3.3 y $3.7 \mathrm{kcal} / \mathrm{g}$ de alimento) sobre la ganancia (GP), conversión alimenticia $(\mathrm{CA})$, proteína retenida (PR), energía retenida (ER) y la relación de eficiencia proteica (REP) en la tilapia del Nilo todos machos (Oreochromis niloticus). En la composición de las dietas se emplearon harina de anchoveta y harina de torta de soya como fuentes de proteína y maíz amarillo duro y subproducto de trigo como fuentes de energía. El aceite de pescado fue añadido para ajustar los niveles de energía requeridos en las dietas experimentales. Se encontraron interacciones altamente significativas $(P<0.01)$ entre la proteína y la energía digestible. Cuando se utilizaron las dietas con $30 \%$ de proteína, el incremento del nivel de energía digestible afectó significativamente la GP, CA, PR, ER y la REP, donde el nivel de $3.3 \mathrm{kcal} / \mathrm{g}$ tuvo el mejor comportamiento. Con $35 \%$ de proteína, el nivel de energía digestible no influyó significativamente sobre la GP, CA, PR, ER y la REP, sin embargo el nivel de 3.0 $\mathrm{kcal} / \mathrm{g}$ tuvo el mayor rendimiento. Cuando se compararon las dos dietas no se observaron diferencias estadísticamente significativas. Considerando el costo de la proteína dietaría se concluyó que la mejor respuesta fue obtenida con la dieta de $30 \%$ de proteína y $3.7 \mathrm{kcal} / \mathrm{g}$ de energía digestible y una relación optima energía digestible/proteína digestible de 13.75 $\mathrm{kcal} / \mathrm{g}$ de proteína.

Palabras clave: proteína; energía digestible; requerimientos nutricionales; Oreochromis

\section{Abstract}

The sparing effect of the dietary protein using diets with high energy levels was evaluated. A factorial design was used to examine the interaction of two levels of protein (30 and $35 \%$ ) and two levels of digestible energy ( 3.3 and $3.7 \mathrm{kcal} / \mathrm{g}$ ) on the weight gain (WG), food conversion $F C)$, retained protein $(P R)$, retained energy (ER) and protein efficiency ratio (PER) in "sex reversal Nile tilapia" (Oreochromis niloticus). Diets contained anchovy and soybean meal as protein sources and yellow corn and wheat bran as energy sources. The fish oil was used to adjust the energy levels. There were highly significant interactions $(P<0.01)$ between the experimental diets. In diets with $30 \%$ proteins, the increase of digestible energy significantly enhances WG, FC, PR, ER and PER, where the level of $3.7 \mathrm{kcal} / \mathrm{g}$ had the best performance. With $35 \%$ protein, the increase of digestible energy had not significant influence on the GP, $\mathrm{CA}, \mathrm{PR}, \mathrm{ER}$ and PER, however the growth of sex reversal Nile Tilapia was improved with the level of $3.3 \mathrm{kcal} / \mathrm{g}$. When were compared both diets, were not find significant differences. Considering the protein cost, it can be concluded that best response was obtained with a diet containing $30 \%$ of protein and $3.7 \mathrm{kcal} / \mathrm{g}$ of digestible energy and optimum digestible energy/ digestible protein ratio of $13.75 \mathrm{kcal} / \mathrm{g}$ protein.

Keywords: protein; digestible energy; nutritional requirements; Oreochromis. 


\section{Introducción}

En general los requerimientos de proteína para el crecimiento de tilapia del Nilo han sido establecidos en un rango de 30\% y $40 \%$, dependiendo del tamańo de la especie, relación proteínaenergía y otras variables experimentales (Siddiki et al. 1988, Stickney 1997, Hafedh 1999).

La proteína es uno de los más importantes nutrientes para el crecimiento de los peces, y a su vez es el componente más costoso de la dieta. Por dicha razón el nivel óptimo de proteína en las dietas para peces ha sido muy bien estudiado. También el nivel de energía en las dietas es crítico para el crecimiento de los peces debido a que niveles altos de energía en las dietas reduce el consumo de alimento y puede resultar en un crecimiento pobre debido a la falta de los nutrientes necesarios. Por otro lado, niveles bajos de energía pueden causar que la proteína sea usada para satisfacer los requerimientos de energía, importantes para el metabolismo basal de los peces, en lugar de ser utilizada para el crecimiento. Por lo tanto, el nivel de energía y proteína en la dieta debe estar en balance para optimizar la producción piscícola.

Se conoce del uso de dietas bajas en proteínas y altas en energía para mejorar la producción de peces (Helland \& Grisdale-Helland 1998, Company et al. 1999; Harpaz et al. 1999, McGoogan \& Gatlin 1999), también, Watanabe et al. (1987) afirmaron que otro beneficio de dietas bajas en proteína y altas en energía es la disminución de los desechos nitrogenados que provienen del metabolismo de los peces. Sin embargo, otros investigadores han reportado efectos no deseables sobre el rendimiento de los peces cuando usaron dietas con altos niveles de energía (Davis \& Arnold 1997, Jover et al. 1999). Estos resultados, probablemente se debieron a la disponibilidad de la energía o porque los requerimientos para los peces son variables, dependiendo de la especie de pez (NRC 1993), contenido de proteína o calidad del alimento (Hillestad \& Johnsen 1994, Jover et al. 1999, Vergara et al. 1999), frecuencia alimenticia (Xie et al. 1997) y tamaño del pez (Mangalik 1986).

No existen muchos estudios acerca de los requerimientos de energía dietaría en tilapia. Yong et al. (1989) recomienda niveles de energía de $4.0 \mathrm{kcal} / \mathrm{g}$ y entre 28 - 30\% de proteína para juveniles de tilapia. Wang et al. (1985), encontraron un crecimiento máximo en juveniles de tilapia del Nilo (Oreochromis niloticus) alimentadas con una dieta de $25 \%$ de proteína y una relación energía/proteína de 14 a $15 \mathrm{kcal} / \mathrm{g}$. Santiago y Laron (1991) estudiaron el efecto de cuatro niveles de proteína y cuatro niveles de energía digestible sobre el rendimiento de la tilapia roja. Encontraron que el mayor rendimiento se obtuvo con $40 \%$ de proteína y una relación optima de $111 \mathrm{mg}$ de proteína/kcal. Cualquiera que sea el método usado para hallar el requerimiento óptimo de energía tilapia del nilo se concluye que utiliza mejor la energía y la proteína provenientes de insumos de origen animal (Hanley 1991).

El propósito del presente estudio fue analizar el efecto ahorrativo de la proteína dietaría, usando dietas con altos niveles de energía y obtener la relación optima energía/proteína que exprese el mayor efecto sobre el rendimiento productivo de "tilapia del nilo todos machos" $O$. niloticus.

\section{Materiales y métodos}

El experimento se ejecutó en el Laboratorio Húmedo de
Huachipa bajo el Conveniio IMARPE-Facultad de Ciencias Biológicas-Universidad Nacional Mayor de San Marcos.

Se utilizaron doce acuarios de vidrio de 50 litros de capacidad. La densidad de carga fue de cinco peces por acuario, con pesos promedios de $25.33 \pm 1.29 \mathrm{~g}$. Siete días antes del inicio del experimento los peces fueron acostumbrados al alimento seco y peletizado a través de la ingestion de una dieta alta en proteína y fortificada con vitaminas y minerales. Los peces se trataron con verde de malaquita y oxitetraciclina a fin de evitar la presencia del hongo Ichthyopthirius y bacterias patógenas. Asimismo, después de cada muestreo se empleó una solución de violeta de genciana o azul de metileno diluido en el agua para evitar ataques bacterianos y fúngicos. Los acuarios se alimentaron con agua de la napa freática almacenada en un tanque elevado de veinte metros cúbicos de capacidad. La dureza del agua fue mantenida a una concentración de $21.90 \pm 0.21 \mathrm{mg} / \mathrm{L}$, considerada como óptima para la tilapia del Nilo. Los acuarios se equiparon con aireadores y termostatos por lo que factores como la temperatura, el oxígeno disuelto y el $\mathrm{pH}$ fueron muy estables. La temperatura promedio fue de $27.50 \pm 0.21{ }^{\circ} \mathrm{C}$, el oxígeno disuelto de $6.83 \pm 0.10 \mathrm{mg} / \mathrm{L}$ y el $\mathrm{pH}$ de $8.42 \pm 0.04$.

La limpieza diaria de los desechos orgánicos del fondo de los acuarios y el recambio diario del agua ayudaron a mantener las condiciones ambientales adecuadas para la realización del experimento.

Las dietas fueron formuladas por programación lineal (Programa LP88) para representar dos niveles de proteína (30\% y $35 \%)$ y dos niveles de energía digestible $(3.0 \mathrm{kcal} / \mathrm{g}$ y $3.3 \mathrm{kcal} / \mathrm{g}$ ) por cada nivel de proteína. En la preparación de las dietas experimentales se utilizaron los insumos alimenticios harina de anchoveta, harina de torta de soya, maíz amarillo duro, subproducto de trigo, aceite hidrogenado de pescado y los aditivos premezcla de vitaminas y minerales, BHT, ácido propiónico y bentonita como ligante. La energía digestible de las dietas fue calculada a partir de los valores calóricos de $3.5 \mathrm{kcal} / \mathrm{g}, 8.1 \mathrm{kcal} / \mathrm{g}$ y 2.5 $\mathrm{kcal} / \mathrm{g}$ para proteína, lípidos y carbohidratos respectivamente (Wilson 1977). Los cálculos de las concentraciones de lisina, metionina, metionina+cistina, calcio y fósforo disponible se hicieron de acuerdo a la NRC (2011), tomando en cuenta los requerimientos para esta especie (Stickney 1997). El análisis químico proximal (AOAC 1990) se realizó para determinar los contenidos de humedad, proteína, lípidos, fibra, ceniza y extracto libre de nitrógeno (ELN) en los insumos alimenticios, en las dietas experimentales. Los insumos y la composición porcentual de las dietas experimentales se observan en la Tabla 1. El contenido de nutrientes se muestran en la Tabla 2 y el análisis proximal de las dietas experimentales se observan en la Tabla 3. La composición química de la carcasa (proteína, lípidos, cenizas y humedad) expresadas en base húmeda se determinó al inicio y al final del experimento sobre la base de una muestra total de 6 peces por tratamiento (AOAC 1990).

Los datos sirvieron para calcular la energía retenida y la proteína retenida. El comportamiento productivo de la tilapia del Nilo se evaluó a través de la ganancia de peso (Hopkins 1992), conversión alimenticia, proteína retenida, energía retenida (Reinitz \& Hitzel 1980) y la razón de eficiencia proteica (Hepher 1993). El alimento fue ofrecido ad-libitum, dos veces al día (08:00 y 16:00 horas). La duración del experimento fue de 45 días. Se empleó un diseño factorial de 2 × 2, con cuatro 
Tabla 1. Insumos y composición porcentual de las cuatro dietas experimentales utilizadas para evaluar el crecimiento de tilapia del Nilo todos machos (Oreochromis niloticus).

\begin{tabular}{lcccc}
\hline & \multicolumn{4}{c}{ Dietas experimentales } \\
\cline { 2 - 5 } Insumos & $\mathbf{1}$ & $\mathbf{2}$ & $\mathbf{3}$ & $\mathbf{4}$ \\
\hline Harina de Pescado & 25.00 & 27.00 & 25.00 & 25.00 \\
Harina de soya & 23.00 & 21.00 & 36.90 & 37.90 \\
Harina de maíz & 44.00 & 40.00 & 30.00 & 27.00 \\
Subproducto de trigo $_{\text {Aceite compuesto }}$ & 2.99 & 0.99 & 4.00 & 1.18 \\
Vitaminas/minerales $^{1}$ & 1.00 & 7.00 & ---- & 5.00 \\
Bentonita & 1.00 & 1.00 & 1.00 & 1.00 \\
BHT & 3.00 & 3.00 & 3.00 & 3.00 \\
\hline
\end{tabular}

${ }^{1}$ Vitaminas (en UI o mg/kg de dietas): A, 5500 UI; D3, 1000 UI; E, 50 UI; K, 10; Colina, 550; Niacina, 100; Riboflavina, 20; Tiamina, 20; D-Pantetonato de Calciio, 50; Biotina, 0.10; Folacina, 5; B12, 20; Acido Ascórbico, 200; Inositol,100. Minerales ( en \% o mg/kg de dieta): Manganeso, 115; Yodo, 2.80; Cobre, 4.30; Zinc, 88; Fierro,44; Cobalto, 0.05; Calcio, 90 \%, Fósforo Disponible, 0.45\%.

Tabla 2. Contenido de nutrientes en porcentajes de las cuatro dietas experimentales utilizadas para evaluar el crecimiento de tilapia del Nilo todos machos (Oreochromis niloticus).

\begin{tabular}{|c|c|c|c|c|}
\hline \multirow[b]{2}{*}{ Nutrientes } & \multicolumn{4}{|c|}{ Dietas experimentales } \\
\hline & 1 & 2 & 3 & 4 \\
\hline Lisina $^{1}$ & 2.04 & 1.98 & 2.41 & 2.42 \\
\hline Metionina $^{1}$ & 0.71 & 0.73 & 0.79 & 0.77 \\
\hline Metionina + Cistina $^{1}$ & 1.11 & 1.12 & 1.27 & 1.24 \\
\hline Calcio $^{1}$ & 0.95 & 1.02 & 0.96 & 0.97 \\
\hline Fósforo Disponible ${ }^{1}$ & 0.25 & 0.30 & 0.24 & 0.29 \\
\hline Energía Bruta (kcal/g) ${ }^{1}$ & 4.01 & 4.29 & 4.00 & 4.24 \\
\hline Energía Digestible $(\mathrm{kcal} / \mathrm{g})^{1}$ & 3.32 & 3.68 & 3.34 & 3.66 \\
\hline Proteína Cruda $(\%)^{1}$ & 30.65 & 30.44 & 35.72 & 35.49 \\
\hline Proteína Digestible $(\%)^{1}$ & 26.76 & 26.77 & 31.25 & 31.22 \\
\hline Relación ED/PD(kcal/g proteína) ${ }^{1}$ & 12.41 & 13.75 & 10.69 & 11.72 \\
\hline
\end{tabular}

${ }^{1}$ Los nutrientes y la energía fueron calculados a partir de los valores publicados por el Consejo Nacional de Investigación-USA (NRC 2011).

Tabla 3. Análisis Proximal (\%) de las cuatro dietas experimentales utilizadas para evaluar el crecimiento de la tilapia del Nilo todos machos (Oreochromis nmiloticus).

\begin{tabular}{lcccc}
\hline & \multicolumn{4}{c}{ Dietas experimentales } \\
\cline { 2 - 5 } Parámetros & $\mathbf{1}$ & $\mathbf{2}$ & $\mathbf{3}$ & $\mathbf{4}$ \\
\hline Humedad & 14.89 & 14.48 & 14.37 & 10.82 \\
Proteína & 30.65 & 30.44 & 35.72 & 35.49 \\
Lípidos & 4.21 & 9.76 & 3.69 & 7.71 \\
Fibra & 3.24 & 2.82 & 4.03 & 3.75 \\
Caniza & 5.75 & 5.76 & 6.34 & 6.38 \\
ELN ${ }^{1}$ & 41.26 & 36.74 & 35.85 & 35.85 \\
\hline
\end{tabular}

${ }^{1}$ Extracto Libre de Nitrógeno

tratamientos y tres repeticiones por tratamiento. Los valores obtenidos fueron sometidos al análisis de variancia y las diferencias entre promedios se determinaron con la prueba de Tuckey, empleando el paquete estadístico Statigraphics version 5.1.

\section{Resultados y discusion}

Se encontraron interacciones altamente significativas $(\mathrm{P}<0.01)$ entre los niveles de energía y proteína dietarias.

En las dietas con 30\% de proteína (PC), el nivel de energía influyó significativamente $(\mathrm{P}<0.01)$ sobre la ganancia de peso. A medida que la energía dietaría se incrementó, la ganancia de peso también se incrementó, siendo más alta con la dieta de 30\% de proteína y $3.7 \mathrm{kcal} / \mathrm{g}$ de energía digestible (ED). No ocurrió lo mismo en las dietas con 35\% de proteína, en las cuales las ganancias de peso fueron estadísticamente iguales, independiente de los niveles de energía dietarios, sin embargo la mayor ganancia de peso se obtuvo con la dieta de $35 \%$ de PC y $3.3 \mathrm{kcal} / \mathrm{g}$ de ED. Al comparar ambas dietas resultó que, estadísticamente las ganancias de peso fueron iguales, razón por la cual se establece que la dieta con $30 \%$ de proteína y $3.7 \mathrm{kcal} / \mathrm{g}$ de energía digestible y una relación optima energía digestible/proteína digestible $(\mathrm{ED} / \mathrm{P})$ de $13.75 \mathrm{kcal} / \mathrm{g}$ de proteína fue las más eficiente en términos de ganancia de peso y ahorro de proteína (Tabla 4).

Fisiológicamente, los lípidos y las proteínas constituyen un componente importante de la estructura de un pez. Si bien, la necesidad de energía calorífica puede evitar su incorporación a los tejidos y obligar a su catabolismo como fuentes energéticas. Así pues, la utilización de la energía y los nutrientes de cada dieta dependerá del nivel de su ingesta y composición. Al igual que otros animales, los peces comen hasta cubrir sus necesidades 
Tabla 4. Ganancia de peso, conversión alimenticia, proteína retenida, energía retenida y relación de eficiencia proteica de alevinos de tilapia del Nilo todos machos (Oreochromis niloticus) alimentados durante 45 días con cuatro dietas experimentales que representaron dos niveles de proteína (30 y $35 \%$ ) y dos niveles de energía digestible (3.3 y $3.7 \mathrm{kcal} / \mathrm{g}$ ) por cada nivel de proteína.

\begin{tabular}{|c|c|c|c|c|}
\hline \multirow[b]{2}{*}{ Parámetros } & \multicolumn{2}{|c|}{$30 \%$} & \multicolumn{2}{|c|}{$35 \%$} \\
\hline & 3.3 & 3.7 & 3.3 & 3.7 \\
\hline $\mathrm{PF}^{1}$ & $38.44 \pm 1.17^{a}$ & $48.57 \pm 0.06^{b}$ & $49.09 \pm 0.49^{b}$ & $48.04 \pm 1.23^{\mathrm{b}}$ \\
\hline $\mathrm{GP}^{2}$ & $51.02 \pm 2.04^{\mathrm{a}}$ & $97.73 \pm 1.91^{\mathrm{b}}$ & $103.01 \pm 0.79^{\mathrm{b}}$ & $90.47 \pm 1.38^{\mathrm{b}}$ \\
\hline $\mathrm{CA}^{3}$ & $3.3 \pm 0.72^{\mathrm{a}}$ & $1.83 \pm 0.22^{\mathrm{b}}$ & $1.85 \pm 0.03^{\mathrm{b}}$ & $2.00 \pm 0.28^{\mathrm{b}}$ \\
\hline $\mathrm{PR}^{4}$ & $22.27 \pm 4.62^{\mathrm{a}}$ & $34.60 \pm 1.96^{\mathrm{b}}$ & $25.54 \pm 1.11^{\mathrm{b}}$ & $28.07 \pm 0.68^{b}$ \\
\hline $\mathbf{E R}^{5}$ & $14.98 \pm 2.99^{a}$ & $20.83 \pm 3.62^{b}$ & $18.19 \pm 1.58^{\mathrm{b}}$ & $19.88 \pm 0.79^{b}$ \\
\hline REP $^{6}$ & $1.04 \pm 0.24^{\mathrm{a}}$ & $1.77 \pm 0.23^{b}$ & $1.54 \pm 0.05^{c}$ & $1.40 \pm 0.11^{\mathrm{c}}$ \\
\hline
\end{tabular}

$a, b, c:$ Letras diferentes dentro filas indican diferencias significativas $(p<0.01)$ por la prueba de Tuckey

${ }^{1}$ Peso Final (g)

${ }^{2}$ Ganancia de peso (\%): (Peso Final-Peso Inicial/Peso Inicial)X100

${ }^{3}$ Conversión Alimenticia: Ingesta de alimento (g)/ganancia de peso (g)

${ }^{4}$ Proteína Retenida: Proteína corporal final-proteína corporal inicial/ingesta de proteína X 100

${ }^{5}$ Energía Retenida: energía corporal final-energía corporal inicial/ingesta de energía X 100

${ }^{6}$ Relación de Eficiciencia Proteica: Ganancia de peso (g)/ proteína ingerida (g)

energéticas (Cho 1987). Contando con que el alimento tiene un balance adecuado de nutrientes, los peces pueden dentro de ciertos límites, compensar un bajo contenido energético de la dieta consumiendo una mayor cantidad de la misma. Este tipo de compensación ocurrirá dentro de los límites de la capacidad física del tracto digestivo, aunque los peces alimentados con una dieta hiperenergética requerirán menos alimento por unidad de ganancia de peso. Sin embargo, al máximo físico de ingesta, los peces alimentados con una dieta rica en energía pueden ingerir más nutrientes y, naturalmente, sostener un mayor crecimiento (Cho et al. 1985). El establecimiento de un óptimo balance de los componentes energéticos es importante debido a que un exceso ó deficiencia de la energía no proteica (carbohidratos y lípidos) puede resultar en una tasa de crecimiento baja. Si la dieta es deficiente en energía no proteica, la proteína será usada para propósitos energéticos (metabolismo basal y actividad voluntaria) y no para síntesis de tejido. Similarmente, si la dieta tiene un exceso de energía no proteica, el apetito o demanda puede ser satisfecha antes que una suficiente cantidad de proteína (y posiblemente otros nutrientes) sea ingerida para satisfacer la demanda para una máxima tasa de síntesis proteica y crecimiento (Cho \& Cowey 1991).

En el presente estudio la dieta alta en energía considerada la más eficiente (30\% de PC y 3.7. kcal/g de ED y una relación óptima ED/PD de $13.75 \mathrm{kcal} / \mathrm{g}$ de proteína) ha permitido que los peces usen la alta energía dietaría para cubrir sus requerimientos energéticos, mejorando de esta manera la eficiencia de utilización de la proteína dietaría para sintetizar mayor masa muscular, que se traduce en una excelente ganancia de peso. De acuerdo con la NRC (1993), 10.7 kcal/g de proteína es una apropiada relación $\mathrm{ED} / \mathrm{P}$ cuando la dieta contiene $28 \%$ de proteína y $3.0 \mathrm{kcal} / \mathrm{g}$ de proteína respectivamente. En este estudio la relación $\mathrm{ED} / \mathrm{PD}$ fue de $13.75 \mathrm{kcal} / \mathrm{g}$ de proteína y fue formulada bajo las recomendaciones de la NRC (2011), sin embargo Wang et al. (1985) demostraron que la relación óptima $\mathrm{ED} / \mathrm{P}$ para crecimiento de tilapia de $6 \mathrm{~g}$ fluctuó entre $14 \mathrm{a} 15 \mathrm{kcal} / \mathrm{g}$ de proteína. Santiago et al. (1982) obtuvieron excelentes resultados alimentando la tilapia del nilo con una dieta de $35 \%$ de proteína. Viola et al. (1994) demostraron que alevinos de tilapia híbrida crecieron muy bien con una dieta de 35\% de proteína. Santiago y Laron
(1991) reportaron para la tilapia roja que el mejor crecimiento fue obtenido con una dieta de $40 \%$ de proteína y una relación proteína/energía de $111 \mathrm{mg}$ de proteína/kcal igual a $9.00 \mathrm{kcal} / \mathrm{g}$ de proteína.

La conversión alimenticia (CA) fue significativamente afectada $(\mathrm{P}<0.01)$ por los niveles de energía en las dietas con $30 \%$ de proteína. La mejor conversión alimenticia (1.83) fue obtenida con el nivel de $3.7 \mathrm{kcal} /$ de energía digestible (Tabla 4). En las dietas con 35\% de proteína los niveles de energía no afectaron significativamente la CA . Sin embargo la dieta con $3.3 \mathrm{kcal} / \mathrm{g}$ de energía digestible mostró una mejor CA (1.85). Cuando se compararon ambas dietas, los valores de CA fueron estadísticamente iguales, por lo que la dieta con $30 \%$ de proteína, $3.7 \mathrm{kcal} / \mathrm{g}$ de energía digestible y una relación óptima ED/PD de $13.75 \mathrm{kcal} / \mathrm{g}$ de proteína fue la más eficiente en términos de ahorro de proteína. Los valores de conversión alimenticia fueron consistentes con los encontrados en otros estudios (Andrews \& Stickney 1972, Webster et al. 1992a, 1992b).

La proteína retenida (PR) fue significativamente influenciada $(\mathrm{P}<0.05)$ por los niveles de energía en las dietas con $30 \%$ de proteína (Tabla 4). La PR fue más eficiente con el nivel de 3.7 $\mathrm{kcal} / \mathrm{g}(34.60 \%)$. Por otro lado con las dietas de 35\% de proteína, la energía dietaría no afectó la PR, siendo estadísticamente igual para ambos niveles de energía (25.54 y 28.07\%). En función de la PR la dieta con $30 \%$ de proteína y $3.7 \mathrm{kcal} / \mathrm{g}$, fue considerada como la mejor en términos de ahorro de proteína. En promedio, para la mayoría de teleósteos la eficiencia de retención de la proteína neta es de alrededor de 40\% (Kaushik 1995), similar a lo obtenido en este estudio con la dieta seńalada como la mejor. Asimismo, este resultado estaría indicando una apropiada relación $\mathrm{ED} / \mathrm{PD}$, que ofrece ventajas como incremento de la economía proteica, mejor retención de nitrógeno y reducción de la excreción de desechos niotrogenados al ambiente (Kaushik \& Médale 1994).

Cuando se evaluó la energía retenida (ER), el nivel de energía dietaría influyó significativamente $(\mathrm{P}<0.01)$, solamente para el nivel de $30 \%$ de proteína dietaría (Cuadro 4). La dieta con $3.7 \mathrm{kcal} / \mathrm{g}$ fue la más eficiente en términos de ER (20.83\%). Por otro lado, para las dietas con $35 \%$ de proteína la ER fue 
estadísticamente igual para ambos niveles energéticos (18.19 y $19.88 \%$ respectivamente). Estos resultados permiten establecer que la dieta con $30 \%$ de proteína y $3.7 \mathrm{kcal} / \mathrm{g}$ fue la de mejor performance en términos de ER y ahorro proteico. Lo encontrado, se explica porque los peces tropicales no solo tienen mejor capacidad para la retención de energía proteica, sino también son hábiles para la mejor utilización de la energía no proteica, ahorrando la proteína para propósito de síntesis de tejidos (Lucket \& Moreau 1989). La alta energía dietaría de la dieta y la adecuada relación ED/PD (13.75 kcal/g de proteína), posibilitó una mayor incorporación de insumos energéticos (maíz amarillo duro, sub producto de trigo y aceite de pescado) como fuentes de energía, ahorrando la proteína para el crecimiento (Kaushik \& Cowey 1991, Kaushik \& Médale 1994, Médale et al. 1995).

En las dietas con 30\% de proteína la relación de eficiencia proteica (REP) fue afectada significativamente por los niveles de energía, alcanzando el valor más alto con el nivel de 3.7 $\mathrm{kcal} / \mathrm{g}$ (Tabla 4). En las dietas con 35\% de proteína, los niveles de energía dietaría no influenciaron significativamente la REP, siendo los valores estadísticamente iguales (Tabla 4). Los valores de la REP obtenidos en este estudio son similares a los valores reportados por Webster et al. (1992b). La literatura indica que el máximo crecimiento de tilapia híbrida se obtuvo con una dieta de $24 \%$ de proteína y una REP de 2.99 (Shiau \& Huang 1989, 1990). Asimismo con dietas de $20 \%$ de proteína en tilapia roja se obtuvo una REP de 2.41, lográndose una mejor eficiencia de utilización de la proteína, al compararse con dietas de mayor nivel de proteína (Clark et al. 1990). Datos similares han sido obtenidos en otros estudios con la carpa cabezona Aristichthys nobilis (Santiago \& Reyes 1991) y en otras especies de tilapia (Teshima et al. 1978, Mazid et al. 1979, Jauncey 1982, Teshima et al. 1985, Siddiki et al. 1988). No obstante El-Sayed y Teshima (1992) encontráron para la tilapia del Nilo el mejor valor de la REP con una dieta de $45 \%$ de proteína y $3.0 \mathrm{kcal}$ de energía bruta/g.

En los estudios sobre tilapia, la literatura muestra un amplio rango de variación en relación a la concentración de proteína dietaría, fluctuando entre 20 y 45\%. Los resultados encontrados en el presente estudio indican que el incremento del nivel de energía digestible independiente del nivel de proteína dietaría usado, mejoró significativamente la ganancia de peso, conversión alimenticia, proteína retenida, energía retenida y la eficiencia proteica; por lo que se puede concluir, considerando las condiciones del experimento y el costo de la proteína, que la mejor respuesta animal se puede obtener con la dieta de $30 \%$ de proteína, $3.7 \mathrm{kcal} / \mathrm{g}$ de energía digestible y la relación óptima energía digestible/proteína digestible de $13.75 \mathrm{kcal} / \mathrm{g}$ de proteína.

\section{Literatura citada}

Andrews J.W. \& R.R. Stickney. 1972. Interaction of feeding rates and environmental temperature on growth, food conversion and body composition of channel catfish. Transactions of the American Fisheries Society 101:94-98.

AOAC (Association of Official Analytical Chemist). 1990. Official methods of analysis. $15^{\text {th }}$ edition. Association of Official Analytical Chemists, Arlington, Virginia, USA. 957 pp.

Cho C.Y. 1987. La energía en la nutrición de los peces. p. 197-243. En: Nutrición en Acuicultura. Vol II. J. Espinosa de los Monteros y U. Labarta Editores. FEUGA-CAYCIT, Madrid, España. 318 pp.

Cho C.Y. \& C.B. Cowey. 1991. Rainbow Trout Oncorhynchus mykiss . pp 131-144. In Handbook of Nutrient Requirement of Finfish (Wilson, R. P. ed.). CRC Press, Florida.
Cho C.Y., C.B. Cowey, T. Watanabe. 1985. Finfish Nutrition in Asia. Methodological Approaches to Research and Development. International Development Research Centre, Ottawa. 154 p.

Clark A.E., W.O. Watanabe, B.L. Olla, R.I. Wicklund. 1990. Growth, feed conversion and protein utilization of florida red tilapia fed isocaloric diets with different protein levels in seawater pools. Aquaculture 88:75-85.

Company R., J.A. Calduch-Giner, S. Kaushik \& J. Pérez Sanchez.1999. Growth performance and adiposity in gilthead sea bream (Sparus aurata): risks and benefits of high energy diets. Aquaculture 171 $(3-4): 279-292$.

Davis D. A. \& C.R. Arnold. 1997. Response of Atlantic croaker fingerling to practical diet formulation with varying protein and energy contents. Journal of the World Aquaculture Society 28 (3):241-248.

El-Sayed A.F. \& S. Teshima. 1992. Protein and energy requirement of nile tilapia Oreochromis niloticus fry. Aquaculture 103:55-63.

Hafedh Y.S. A. 1999. Effects of dietary protein on growth and body composition of Nile tilapia, Oreochromis niloticus L. Aquaculture Research 30:385-393.

Hanley F. 1991. Effects of feeding supplementary diets containing varying levels of lipid on growth, food conversion, and body composition of Nile tilapia, Oreochromis niloticus (L.). Aquaculture 93: 323-334.

Harpaz S., S. Sklan, I. Karplus, A. Barki \& Y. Noy. 1999. Evaluation of juvenile perch Bydianus bydianus (Mitchel) nutritional needs using highand low-protein diets at two feeding levels. Aquaculture Research 30: 603-610.

Hellan S.J. \& B. Grisdale-Helland. 1998. Growth, feed utilization and body composition of juvenile Atlantic halibut (Hippoglossus hippoglossus) fed diets differing in the ratio between the macronutrients. Aquaculture 160:49-56.

Hepher B. 1993. Nutrición de peces comerciales en estanques. Primera Edición. Editorial Limusa, Mexico. 406 pp.

Hillestad M. \& F. Jonhsen. 1994. High-energy/low-protein diets for Atlantic salmon:effects on growth, nutrient retention and slaughter quality. Aquaculture 124:109-116.

Hopkins, K.D. 1992. Reporting Fish Growth: A review of the Basis. Journal of the World Aquaculture Society, 23 (3): 173-179.

Jauncey K. 1982. The effect of varying dietary protein level on the growth, food conversion, protein utilization and body composition of juvenile tilapias (Sarotherodon mossambicus). Aquaculture 27:43-54.

Jover M., A. García-Gómez, A. Tomas, F. De la Gandara \& L. Pérez. 1999. Growth of Mediterranean yellowtail (Seriola dumerilli) fed extruded diets containing different levels of protein and lipid. Aquaculture $179: 25-33$

Kaushik S.J. 1995. Amino acid requirement, protein and energy utilization in fish. In: Symposium From Feed to food. Utrecht, Netherlands. Victam International. Feed and Food Industries Show.

Kaushik S.J. \& C.B. Cowey. 1991. Ammoniogenesis and dietary factors affecting nitrogen excretion. In: Cowey C.B, Cho, C. Y., eds. Nutritional Strategies and Aquaculture Waste. Guelph, Canada: Univ. Guelph. P 3-19.

Kaushik S.J. \& F. Médale. 1994. Energy requirements, utilization and supply to salmonids. Aquaculture. 124:81-97.

Mangalik, A. 1986. Dietary energy requirements of channel catfish. Doctoral dissertation. Auburn University, Auburn, Alabama, USA.

Mazid M.A., Y. Tanaka, T. Katayama, M.A. Rhaman, K.L. Sympson, C.O. Chichester. 1979. Growth response of Tilapia zilli fingerling fed isocaloric diets with variable protein levels. Aquaculture 18:115-122.

McGoogan B. B. \& D. M. Gatlin. 1999. Dietary manipulations affecting growth and nitrogenous waste production of red drum, Sciaenops ocellatus. Effects of dietary protein and energy levels. Aquaculture 178:333-348.

Médale F., C. Brauge, C.F. Vallée \& S.J. Kaushik. 1995. Effects of dietary protein/energy ratio, ration size, dietary energy source and temperature on nitrogen excretion in rainbow trout. Water Sci. Technol. 31 (10): 185-195.

NRC. (National Research Council). 1993. Nutrient requirements of fish. National Academy Press. Washington D.C. USA.

NRC (National Research Council), 2011. Nutrient requirements of fish and shrimp. National Academy Press. Washington, D.C. USA.

Reinitz G. \& F. Hitzel. 1980. Formulation of practical diets for rainbow trout based desire performance and body comparison. Aquaculture, 19: 243-52. 
Santiago C.B., M. Babes-Aldaba, M.A. Laron. 1982. Dietary crude protein requirement of Tilapia nilotica fry. Phillippines J. Biology, 11:255265.

Santiago C.B. \& O.S. Reyes. 1991. Optimum dietary protein level for growth of bighead carp Aristichthys nobilis fry in a static water system. Aquaculture 93:155-162.

Santiago C.B. \& M. A. Laron. 1991. Growth response and carcass composition of red tilapia fry fed diets with varying protein levels and protein to energy ratio. Pages 55-62. In S. S. DeSilva, ed. Proceeding of the Third Asian Fish Nutrition Network Meeting. Special Publication of the Asian Fisheries Society, Manila, Philippines.

Shiau S.Y. \& S.L. Huang. 1989. Optimal dietary level for hybrid tilapia (Oreochromis niloticus x O. aureus) reared in seawater. Aquaculture 81:119-127.

Shiau S.Y. \& S.L. Huang. 1990. Influences of varying energy levels with two protein concentration in diets for hybrid tilapia (Oreopchromis niloticus x O. aureus) reared in seawater. Aquaculture 82:110-117.

Siddiqui A., M.S. Honlander \& A.A. Adam. 1988. Effects of dietary protein levels on growth, feed conversion and protein utilization in fry and young tilapia, Oreochromis niloticus. Aquaculture 70: 63-73.

Statigraphics, 1991. Statical Graphics System. Statical Graphics Corporation. MD. USA.

Stickney R.R. 1997. Tilapia Nutrition, feeds and feeding. In:Tilapia Aquaculture in the Americas. World Aquaculture Society. (1): 34-54.

Teshima S., A. Kanasawa \& Y. Ushiyama.1985. Optimum protein levels in casein-gelatin diets for Tilapia niloticus fingerling. Mem. Fac. Fish, Kagoshima Univ.34:45-52.

Teshima S., G.M.O Gonzales \& A. Kanazawa. 1978. Nutritional requirements of tilapia: utilization for dietary by Tilpai zilli. Mem Fac. Fish, Kagoshima Univ. 27:49-57.
Vergara J.M., G. Lopez-Calero, L. Robaina, M.J. Caballero, D. Montero, M.S. Izquierdo, \& A. Aksnes. 1999. Growth feed utilization and body lipid content of gilthead seabream (Sparus auratus) fed increasing lipid levels and fish meal of different quality. Aquaculture 179:35-44.

Viola S., H. Angeoni, N. Gur \& E. Lahav. 1994. Growth performance, protein and energy balances of hybrid tilapia fed two levels of lysine at three levels of protein. Bamidgeh 46:212-222.

Wang K. W., T. Takeuchi \& T. Watanabe. 1985. Optimum protein and digestible energy levels in diets for Tilapia nilotica. Bulletin of the Japanese Society of Scientific Fisheries 51: 141-146.

Watanabe T., T. Takeuchi, S. Satoh, T. Ida and M. Yagichi.1987. Development of low protein-high energy diets for practical carp culture with special reference to reduction of total nitrogen excretion. Bulletin of the Japanese Society of Scientific Fisheries 53 (8):1413-1423.

Webster C D., D.H. Yancey \& J.H. Tidwell. 1992b. Effects of partially or totally replacing fish meal with soybean meal on growth of blue catfish, Ictalurus furcatus. Aquaculture 103:141-152.

Webster C.D., J.H. Tidwell, I.S. Goodgamed, D.H. Yancey \& I. Mackey. 1992a. Use of soybean meal and distillers grains with soluble as partial or total replacement of fish meal in diets for channel catfish, Ictalurus punctatus. Aquaculture 106:301-309.

Wilson R.P. 1977. Energy relationships in catfish diets. Pp 21-29. In: Nutrition and feeding of channel catfish. R. R. Sticney and R. T. Lovell (Editors). Southern Cooperative Series. Bull. 218.

Xie S., Y. Cui, Y. Yang \& J. Liu. 1997. Effect of body size on growth and energy budget of Nile tilapia (Oreochromis niloticus). Aquaculture 157:25-34.

Yong W.-Y., T. Takeuchi \& T Watanabe.1989. Relationship between digestible energy contents and optimum energy to protein ratio in Oreochromis niloticus diets. Bulletin of the Japanese Society of Scientific Fisheries 55:869-873. 